\title{
USE OF A RECIPROCAL TRANSPLANT STUDY TO MEASURE THE RATE OF PLANT COMMUNITY CHANGE IN A TIDAL MARSH ALONG A SALINITY GRADIENT
}

\author{
Paul R. Wetzel ${ }^{1}$, Wiley M. Kitchens, Janell M. Brush, and Marsha L. Dusek \\ Florida Cooperative Fish \& Wildlife Research Unit \\ University of Florida \\ Gainesville, Florida USA 32611-0485 \\ ${ }^{1}$ Department of Biological Sciences \\ Clark Science Center \\ Smith College \\ Northampton, Massachusetts USA 01063
}

Abstract: In a tidal marsh on the Savannah River (Georgia, USA), rate of plant community change along a salinity gradient was measured using a reciprocal transplant study. Donor sods were moved in all possible combinations from freshwater/oligotrophic to mesohaline sites and from mesohaline to freshwater/oligohaline sites at four different locations. The reciprocal aspect of the experiment also allowed the determination of how the rate of plant community change is affected by the direction and level of displacement along the salinity gradient. Stem densities of each species were counted in each transplanted plot in June and October for a 30 month period. Plant community structure and composition changed by a significantly measurable amount within 6 to 18 months of a change in salinity. However, the time required for the transplanted sods to resemble their surrounding communities (at the $\mathrm{p} \leq 0.05$ level) ranged from 6 to more than 30 months, with some transplanted sods never resembling the surrounding plant communities during the study period. If fresh-or oligohaline sods were moved to more saline environments, environmental conditions appeared to have an overriding effect on the vegetation and community change was rapid, occurring in $6-10$ months (mean $=9.3$ months, $\mathrm{SE}=1.9$ ). Shifts from mesohaline to fresher sites on the salinity gradient delayed community change to about 18 months (mean 
$=15.3$ months, $\mathrm{SE}=1.7$ ) and appeared to be controlled by biotic factors such as vegetative expansion and interspecific competition.

Key Words: vegetation change, Savannah River, tidal marsh, salinity, gradient, transplant experiment

\section{INTRODUCTION}

Plant zonation along a salinity gradient is a major characteristic of temperate coastal marshes (Odum 1988, Mitch and Gosselink 2000). Salinity regimes within the marsh fluctuate along a gradient during storm surges and hurricanes (Chabreck and Palmisano 1973, Gutenspergen et al. 1995) and more permanently because of hydrologic alterations such as tide gates, levees (Roman et al. 1984, Pearlstine et al. 1993) and sea level rise (DeLaune et al. 1987, Warren and Niering 1993), shifting plant zonation and reorganizing the plant communities. How rapidly plant communities respond to fluctuations in the salinity gradient has been limited to studies of individual species for relatively short time periods, about 6 weeks to four months (McKee and Mendelssohn 1989, Flynn et al. 1995, Howard and Mendelssohn 1999b). Several aspects of a fluctuation in salinity influence community change. Howard and Mendelssohn (1999) found that the final salinity level reached during a salinity fluctuation and the duration of the exposure were the two most important determinants of mortality and, by extension, community change. Salinity and water levels after a saltwater intrusion event also had important effects on community change (Flynn et al. 1995).

The magnitude and rate of plant community response to salinity fluctuations also depend on the structure and composition of the existing plant community. Response of 
freshwater marshes to salinity fluctuations may depend on one or more factors: species composition, duration, level, and abruptness of salinity exposure, flooding depth, and a propagule source of more salt-tolerant species (McKee and Mendelssohn 1989).

Interspecific competition is also an important factor in plant community change, particularly in the less stressful freshwater and intermediate salinity plant communities (Snow and Vince 1984, Bertness and Ellison 1987, Pennings and Callaway 1992, Hacker and Bertness 1999). Salinity fluctuations have less effect on brackish plant communities (Visser et al. 1999), but these communities are subject to physical disturbances such as wrack deposits (Brewer et al. 1998, Brinson and Christian 1999) and storm surges (Gutenspergen et al. 1995).

While considering the effect of external disturbance factors on a southeast freshwater tidal marsh in the lower Savannah River basin (Georgia, U.S.A.) (Kitchens, unpublished data), field observations of marsh communities along the salinity gradient indicated that community associations and the dominance of individual species rapidly changed in a relatively short period of time. It was further noticed that the rate of community change varied along the salinity gradient; a change in salinity in freshwater communities having a more pronounced effect on rate of plant community change than salinity changes in brackish communities. This study investigated the rate of plant community change using a reciprocal transplant study along the salinity gradient. The objectives of this study were to 1 . Measure the rate of plant community change across a salinity gradient, and 2 . Determine how the rate of plant community change is affected by the direction and level of displacement along the salinity gradient. 


\section{METHODS}

\section{Study Area and Data Collection}

The study area covered 1,900 ha of Savannah River tidal marsh in Chatham County, Georgia and Jasper County, South Carolina within the boundaries of the Savannah National Wildlife Refuge. Local tides measure $2.0-2.5 \mathrm{~m}$ (de la Cruz 1981) and spring tides on the refuge reached $2.75 \mathrm{~m}$. The study area is drained by a network of human made canals, historic artifacts of $18^{\text {th }}$ and $19^{\text {th }}$ century rice farming. Plant zonation associated with the historic canals is conspicuous, although present vegetation is consistent with noncultivated, naturally occurring tidal marshes of the southeastern coast (Odum et al. 1984). The study area is also drained by the Little Back River and Middle River, tributaries to the Savannah River, as well as the Front River which becomes the main channel of the Savannah River downstream. All three of these river channels flow roughly parallel to each other through the study site (Figure 1).

Four sample sites were located on the Back River and were chosen to represent tidal freshwater (site B1, interstitial salinity $\leq 0.5 \mathrm{ppt}$ ), fresh/intermediate (site B2, interstitial salinity $0.3-1.7 \mathrm{ppt}$ ), intermediate (site B3, interstitial salinity $0.5-3.0 \mathrm{ppt}$ ), and brackish (site B4, interstitial salinity 2.0-11.0 ppt) marsh conditions (Figure 2). The rate of plant community change across the freshwater - brackish (B1-B4) sample sites was measured using a reciprocal transplant study initiated in January 2001 when plants were senescent and seed and pollen transfer between plots would be minimal. Areas within sample sites B1-B4 that were at least $40 \mathrm{~m}$ from any canals and representative of the general vegetation near each sample site were chosen as donor plots. Four adjoining $1 \mathrm{~m}^{2}$ 
plots were excavated to a depth of $10 \mathrm{~cm}$ using spades and saws. Each $1 \mathrm{~m}^{2}$ piece of sod was further divided into four equal donor pieces of sod and placed on plastic during transport to the new location. Vegetation and substrate were excavated from $1 \mathrm{~m}^{2} \times 10 \mathrm{~cm}$ deep receiver sites at the freshwater - brackish sample sites. The donor sod pieces were randomly assigned to a receiver site at each sample site. Professional grade plastic lawn edging (12.7 cm deep) was placed between donor sod quadrats to prevent vegetative growth between the newly transplanted sods. Keeping the transplanted sods together allowed them to be exposed to the same environmental conditions and meant that the sods were exposed to the surrounding plant community on two sides. The transplant process was replicated four times and all sods were excavated and re-planted within 42 hours.

Non-destructive vegetation sampling of the receiver plots was conducted in June and October from $2001-2003$. Stem densities of each species were counted in each 0.25 $\mathrm{m}^{2}$ transplanted plot. Many transplant plots contained very dense vegetation growing in distinct clumps. In the areas of dense growth stems of each species were counted in a 12.5 $\mathrm{cm}^{2}$ subplot and these stem densities were multiplied by the percent aerial cover of each species in the uncounted portion of the $0.25 \mathrm{~m}^{2}$ transplant plot. If a species grew in the easily countable and dense areas of the transplant plot then the stem counts were added together to produce a stem density estimate for the entire $0.25 \mathrm{~m}^{2}$ transplant plot.

To measure salinity double-nested PVC wells were placed at each sample point. The inner well was placed $30 \mathrm{~cm}$ into the soil to collect interstitial pore water through vertical slits below the soil surface. The outer casing was placed $20 \mathrm{~cm}$ into the soil to prevent surface water from entering the inner well. Initially, salinity was measured in situ with a YSI salinity/conductivity meter (Yellow Springs Instrument). In October 2001, one 
automated salinity recorder (YSI 600 XIM Sonde, Yellow Springs Instrument) was installed at each sample site $70 \mathrm{~m}$ from the canal edge. The sondes were housed in identical vented wells anchored to the marsh surface with salinity sensors located within the $10 \mathrm{~cm}$ root zone of the marsh. Interstitial soil salinity $10 \mathrm{~cm}$ below soil surface and water depth from 0.01 to $1.5 \mathrm{~m}$ above the soil surface were recorded continuously at 15 minute intervals.

Data Analysis

Plant community rate of change between sites was measured with multi-response permutation procedure (MRPP). MRPP is a nonparametric procedure that tests the null hypothesis of no difference between two or more groups (matrices). The procedure calculates the average within group distance for each group in species space. The test statistic, $T$, describes the separation between the groups where the more negative a $T$ value, the greater the distance between groups. A p-value is calculated by comparing the average within group distance of the known matrix to the mean within group distance of all possible partitions of the data. More detailed descriptions of the MRPP are given in Mielke and Berry (2001) and McCune and Grace (2002). All MRPP analyses were done using PC-ORD v. 4.0 (McCune and Mefford 1999). Distances in species space were calculated with Sørensen distance, a measure that retains the sensitivity of heterogeneous data sets and does not exaggerate the influence of outliers (McCune and Grace 2002).

Plant species with stem counts of less than $5 \%$ frequency were eliminated from the analyses resulting in matrices with 37 species by 4 replicates for each sample date. Plots were sampled five times for a total of 80 samples ( 4 sites $\times 5$ dates $\times 4$ replicates). Comparisons were made between the transplanted sods (donor sod) with the original plant 
community. For example, a piece of sod from the brackish site (B4) transplanted into the freshwater (B1) site was compared to the brackish site. Since the donor communities were not sampled initially, it was assumed that the plant community of the donor sod was not different from the plant community from which it came and that the test statistic, $T$, was approximately equal to 0 . This assumption provided a convenient and logical starting point for the analysis. As time passed, the test statistic will become more negative if the transplanted donor sod changes into the community that it was transplanted and becomes less like the community from which it originated.

Community comparisons were also made between the donor sod and the receiving community. This was done to measure how fast the donor sod became similar to the surrounding receiving community. Thus, two measurements were made on each transplant combination at each sample date: $a$. the difference between the transplanted community and the community from where it originated, and $b$. the difference between the transplanted community and the receiving community. From these measurements, the following metrics were calculated:

Time to Sustained Plant Community Change (months)-the time required for the structure and composition of the plant community of a donor sod to change enough to be statistically different from the plant community of origin. Statistical significance had to occur for three or four sample dates in succession to be considered a sustained plant community change.

Cumulative Change-the absolute value of the difference in Test Statistic ( $\mathrm{T}$ ) between two sample dates were added together and plotted through time. 
Rate of Cumulative Community Change (Test Statistic, T/30 months)-the cumulative community change value at 30 months since transplanting the sods was divided by 30 months to calculate the rate.

\section{RESULTS}

Species richness at the sample sites ranged from 20 species at the freshwater site (B1) to three species at the brackish site (B4) (Table 1). Most of the species (72\%) at the sample sites were rhizomatous perennials. Annuals were more common at the freshwater and freshwater/intermediate sites (sites B1-B2) (Table 1). Eleocharis montevidensis dominated the freshwater and freshwater/intermediate sites, while Scirpus validus dominated the intermediate and brackish sites (Table 1). Two exotic species were recorded Alternanthera philoxeroides and Murdannia keisak, with $M$. keisak being well established at the freshwater site (B1) (Table 1). The plant community composition, species diversity, zonation overlap and life history strategies of the sample sites suggest that the study area was nearly all tidal freshwater marsh (Odum 1988).

Water levels at the freshwater-intermediate sites were similar, ranging from -3 to $+2 \mathrm{~cm} 85 \%$ of the time (Figure 2). These sites experienced hydrologic pulses that caused water levels to go as high as $40-70 \mathrm{~cm}$, but water levels at those depths occurred infrequently, $1-3 \%$ of the time (Figure 2). The brackish site had a greater tidal influence and the highest water levels of any of the sample sites, with a water depth of $3 \mathrm{~cm} 50 \%$ of the time (Figure 2). This study was partly conducted during a regional drought that began in June 1998 and lasted until the end of 2002 and these weather conditions probably created below normal water conditions during part of the experiment. 
Salinity levels at the freshwater and freshwater/intermediate sites (B1 and B2) ranged from $<0.5$ to $1.7 \mathrm{ppt}$ and were similar and generally consistent throughout the study period (Figure 2). Interstitial salinity levels at the intermediate site (B3) were higher, ranging from 0 to $2.7 \mathrm{ppt}$, and also remained consistent throughout the study period. At the brackish site (B4), salinity levels varied between 1 and $11 \mathrm{ppt}$ and were at least $7.0 \mathrm{ppt}$ half the time during the study period (Figure 2). Salinity pulses ranging from 9-11 ppt occurred about $4 \%$ of the time during the period of record (Figure 2 ).

The rate of plant community change along the salinity gradient depended on the direction of transplanting - fresh to more saline or saline to more fresh. Overall, the freshwater sods transplanted into a saline site took an average of 9.3 months to change into a statistically different plant community (Table 2). Sustained community change of saline sods transplanted into fresher sites took longer, 15.3 months ( $t-$ test, $p=0.04)$. It is interesting to note that transplanting any donor sod into any receiver site caused the plant community of the donor sod to eventually change enough to be statistically significant (at $\mathrm{p} \leq 0.05$ level).

The rate of plant community change also depended on the difference in salinity levels between the donor community and the receiver community. Plots of the Test Statistic, T, and cumulative change in $T$, between transplant sod and the control sod (community of origin) through time produced two general patterns (Figure 3 ). If salinity levels were $>1 \mathrm{ppt}$ between donor and receiver sites, then transplanting a sod from a freshwater location into a saline site produced a rapid (6 - 10 months), sustained change in the plant community (Table 2). Cumulative change of the Test Statistic generally leveled off in 18 months although the intermediate sod transplanted into the brackish site was still 
rising at 30 months (Figure 3, Table 2). Sustained community change was delayed to at least 18 months when sods were moved from saline to a more fresh location (Table 2). Cumulative change had not leveled after 30 months (Figure 3, Table 2). Rates of community cumulative change of the saline sod planted into a freshwater site were nearly double the cumulative change levels of a freshwater sod transplanted into a more saline site after 30 months (Table 2).

If salinity levels were $<1 \mathrm{ppt}$ between donor and receiver sites, transplant direction generally made little difference for these transplant combinations. Time to sustained change in the plant community varied between 6 to 18 months (Table 2). Freshwater (site B1), freshwater/intermediate, and intermediate (sites B2 and B3) plant communities were clearly in greater flux: cumulative change continued to rise after 30 months at four of the six transplant combinations (Figure 3, Table 2). Rates of community change were similar to transplant combinations when mean salinity difference between donor and receiver plots were $>1$ ppt (Table 2). Transplant combination freshwater/intermediate $\rightarrow$ freshwater was unusual in that the plant community significantly changed in 10 months and did not change after that date, while all other low saline sites continued to fluctuate during the next 20 months (Figure 3). Consequently, this transplant combination also had one of the lowest rates of community change $(0.09$, Table 2$)$.

The time required for the donor sods to resemble the surrounding plant communities varied between 6 and $>30$ months and was not dependent on the direction of transplanting (Table 3). However, donor sods became like their surrounding communities in 6 to 10 months when the difference between donor and receiver plots was $>1 \mathrm{ppt}$ compared to 18 to $>30$ months when the salinity difference was less than 1 ppt (Table 3 ). 
The brackish $\leftrightarrow$ freshwater combinations were the exception to this pattern as the donor sods for both combinations were statistically different from the surrounding plant community even after 30 months (Table 3 ).

A species analysis of the changes occurring in the reciprocal transplant combinations indicated that species richness declined by 21 to $82 \%$ when freshwater communities were transplanted into more saline environments (Table 4). Between 0-3 species $(0-16 \%)$ were added in these conditions. The trend reversed when saline communities were transplanted into more fresh environments: although 2-3 species were lost, 3-17 species were gained and overall species richness increased 38-81\% (Table 4).

Mean number of stems of the dominant plant species varied according to individual species' salinity tolerances and the difference in salinity levels between the donor and the receiver sites. The transplanting of freshwater communities into saline environments caused the mean number of stems of Murdannia keisak to always decline. Zizaniopsis milacea (Michx.) Doell \& Aschers. stems also either stayed the same or declined to zero (Table 4). Scirpus validus Vahl nearly always increased and Spartina cynosuroides (L.) Roth always increased when transplanted into the brackish site (B4), the most saline site (Table 4). Eleocharis montevidensis clearly is not tolerant of high salinities and usually declined when transplanted into more saline environments (Table 4).

The species $M$. keisak, E. montevidensis, and $Z$. milacea rapidly colonized saline sods moved to fresher sites, as observed with the increase in the mean number of stems for all three species (Table 4). S. cynosuroides stems declined and disappeared except when transplanted into intermediate site (B3). S. validus generally declined in the fresher 
environments, but did increase when transplanted into the fresh/intermediate and intermediate salinity sites (Table 4).

\section{DISCUSSION}

Shifts in the salinity gradient can alter plant community structure and composition in as little 6 months, although 18 to more than 30 months were needed for a transplanted sod to resemble the surrounding plant community. The rate of community change depended on the direction of displacement along the salinity gradient. If fresh-or intermediate sods were moved to more saline environments, environmental conditions appeared to have an overriding effect on the vegetation and community change was rapid, occurring in 6-10 months. Shifts from brackish to fresher sites on the salinity gradient delayed community change to about 18 months and appeared to be controlled by biotic factors such as vegetative expansion and interspecific competition. However, the time required for the transplanted sods to resemble their surrounding communities (at the $\mathrm{p} \leq 0.05$ level) ranged from 6 to more than 30 months, with some transplanted sods never resembling the surrounding plant communities during the study period. We know of no other studies that have measured rate of community vegetation change in tidal marsh communities.

The faster rate of community change when freshwater sods were moved to more saline sites was caused by the decline or death of the freshwater/intermediate species. Survival of freshwater species depends on the final salinity level and duration of salinity exposure (Howard and Mendelssohn 1999b). Total species loss increased steadily with the increasing difference in salinity between the donor and receiver plots: $5 \%$ of the species 
were lost when mean salinity increased $0.18 \mathrm{ppt}$ compared to $71 \%$ of the species lost with a $5.56 \mathrm{ppt}$ increase in mean salinity (Table 4). Saltwater tolerance varies with individual species and has been well documented (Snow and Vince 1984, McKee and Mendelssohn 1989, Howard and Mendelssohn 1999a). Some species, such as Murdannia keisak, a dominant freshwater species in this study, have no tolerance for saline waters. Other species, such as Scirpus validus, tolerate a wide range of salinity levels and grew throughout the project area (Table 4; Latham et al. 1991).

Community change was generally slower when saline sods were moved to more fresh sites. Possible reasons for a slower community shift are that existing species in the donor sod must be competitively excluded, freshwater plant propagules had to be dispersed into the donor sod, and vegetative encroachment from the surrounding community had to occur. Most saline tolerant species grow quite well in fresh water, but are not present in freshwater communities because they cannot compete with the freshwater species (Bertness and Ellison 1987, Hacker and Bertness 1999). The fact that the cumulative change curves for all of the saline to fresher transplant combinations (except freshwater/intermediate $\rightarrow$ freshwater and intermediate $\rightarrow$ freshwater/intermediate) were still increasing at 30 months indicates continued fluctuation in community change (Figure 3 ). That continued fluctuation may be the result of interspecific competitive interactions at these sites. Competitive exclusion and successional change will simply take longer than community change caused by the immediate die-back of freshwater species that occurred when fresh sods were transplanted into more saline environments.

The biological relevance of the time required for vegetation communities to change enough to be statistically significant is difficult to determine. However, the time required 
before a transplanted sod resembled its surrounding community helps to understand the rate of community change along the salinity gradient. The donor sods often resembled surrounding plant communities at a number of locations on the salinity gradient, sometimes two or three at the same time (Table 3). In general, the time to when the donor sod was not statistically different from the surrounding community was 12 to 18 months longer than the time to sustained plant community change within the donor sod (Tables 1 and 2).

In December, 2002 (month 24 in the experiment), a four year regional drought ended in the Savannah River watershed (Kitchens, unpublished data). Salinity levels at all four sites greatly decreased (from 44 to $82 \%$ ) by June, 2003 (month 30 in the experiment) and hydrology resumed a more normal pattern. The end of the drought caused a shift in the salinity gradient for the plant communities at the freshwater and intermediate sites.

Freshwater sods from sites B1 and B2 that had been transplanted into more saline intermediate sites became more like their donor communities, indicated by a rise in the cumulative change lines for these transplant combinations (Figure 3, upper left panel). Sods transplanted into the brackish site showed no community change from the end of the drought (Figure 3, lower left panel). The effect of the end of the drought is also apparent for many transplant combinations as the donor sods resemble plant communities from a "fresher" location on the salinity gradient (Table 3). However, it is impossible to determine from these data which community - the donor sod, the adjacent community, or both - had changed to resemble plant communities at a different point along the salinity gradient.

Since communities were only sampled at two specific times in the growing season instead of continuously, the time to sustained community change and time required to 
resemble the surrounding vegetation reported in this study may be influenced by the sampling schedule. However, McKee and Mendelssohn (1989) transplanted freshwater/intermediate sods into an intermediate marsh with salinity levels 10 ppt greater than the donor marsh, killing all the original vegetation. Although the hydrologic regime was an important factor, recolonization of the denuded sods from the adjacent community went from zero to densities of 12 to 20 stems $\left(\# 0.1 \mathrm{~m}^{-2}\right)$ in four months. Such stem densities are comparable to changes in stem densities in many of the plots in this study (Table 4).

Two studies in New England marshes (interstitial salinity 19-30 ppt) also provide a time measure of successional change that can be related to this study. Bertness and Ellison (1987) report that bare patches caused by wrack deposits in Spartina patens vegetation zones similar in size to the transplanted sods use in this study were completely colonized in two growing seasons ( $\sim 16$ months) and within two years in Juncus gerardi zones. Hartman (1988) reported that Spartina alterniflora expanded into bare patches at an average rate of $12 \mathrm{~cm} /$ year. Like the species from the New England marshes, the dominant species in this study were perennials that colonize vegetatively with rhizomes. Vegetative expansion from two directions into the sod transplants would cover the sod areas in two growing seasons at the rates reported by Bertness and Ellison (1987) and Hartman (1988), similar to the results found in this study. It would be expected that the warmer temperatures and longer growing season at the Savannah River marsh would have increased the rate of colonization. However, surrounding perennials in this study were expanding into sods already occupied with plants, not bare patches (there were no wrack deposits observed in the study area), and this may have increased the length of time required for complete colonization. 
Shifts in the salinity gradient cause the transformation of large areas of the tidal marsh vegetation community. One limitation of this study is that community change at the scale of a $0.25 \mathrm{~m}^{2}$ sod - a scale that allows the small transplanted area to be readily colonized by the adjacent community - may not realistically represent vegetation change on a landscape scale. However, the time scale of the vegetation change described in this study is similar to the changes observed in the proportion of community associations through time (Kitchens, unpublished data). It was observed that the proportion of these community associations expanded or contracted through time in a 6 to 30 month time frame.

The seasonal effect of the sampling schedule may have also affected the results of this study. Sods were transplanted in January, 2001 and measured in June and October of that year. Community change between transplant combinations with a difference in salinity greater than $0.70 \mathrm{ppt}$ between the donor and receiver sites (all combinations except freshwater/intermediate $\rightarrow$ freshwater and intermediate $\rightarrow$ freshwater/intermediate) was not statistically different in October (Figure 3), suggesting that the composition and structure of the saline communities were similar to less saline communities in October. This pattern is clearly apparent in Table 3 on the October, 2001 sample date as the transplanted sod is not statistically different from two or three other sites on the salinity gradient.

The results of this study can be usefully applied to predicting vegetation changes in the tidal marsh from human alterations. For example, the desire to dredge the Savannah River Harbor $30 \mathrm{~m}$ deeper to increase commercial shipping capacity has resulted in an interest in modeling the effect of that action on the tidal marsh vegetation. Our results provide parameter guidelines for modeling tidal marsh succession caused by sustained 
salinity fluctuations. Clearly, models must consider the direction of the salinity shift and they must run two to three years to adequately capture changes in vegetation.

In conclusion, sustained fluctuations in the salinity gradient can alter plant communities in as little 6 months, although 18 to more than 30 months were needed for the transplanted sod to resemble the surrounding plant community. The rate of community change depended on the direction of displacement along the salinity gradient.

Environmental conditions appeared to have an overriding effect on the vegetation if freshor intermediate sods were moved to more saline environments. Community change was rapid, occurring in 6-10 months. Shifts from brackish to fresher sites on the salinity gradient delayed community change to about 18 months and appeared to be controlled by biotic factors such as vegetative expansion and interspecific competition. Our results indicate that tidal marsh communities are very dynamic and can rapidly respond to changing environmental and biotic conditions.

\section{ACKNOWLEDGMENTS}

We gratefully acknowledge the contributions of the following people and agencies for their invaluable contributions to this study. Funding was provided by the Georgia Ports Authority, U. S. Fish and Wildlife Service, and U. S. Army Corps of Engineers. The management and staff of the Savannah Coastal National Wildlife Refuge Complex were particularly accommodating in providing facilities and in-kind support. We are especially thankful to John Robinette, Russell Webb, and Robert Ron.

We are most indebted to the graduate student and field technician corps of the Florida Cooperative Fish and Wildlife Research Unit. Scott Berryman, Zachariah Welch, 
Jamie Duberstein, Kate Malloy, Victoria Dreitz, Kristianna Lindgren, and John Kitchens all contributed either to the massive effort of moving sod blocks of marsh from one end of the gradient to the other (and all points in between) or provided the incredible patience and attention required to count plant stems in situ. 


\section{LITERATURE CITED}

Bertness, M. D. and A. M. Ellison. 1987. Determinants of pattern in New England salt marsh plant community. Ecological Monographs 57:129-147.

Brewer, J. S., J. M. Levine, and M. D. Bertness. 1998. Interactive effects of elevation and burial with wrack on plant community structure in some Rhode Island salt marshes. Journal of Ecology 86:125-136.

Brinson, M. M. and R. R. Christian. 1999. Stability of Juncus roemeriamus patches in a salt marsh. Wetlands 19:65-70.

Chabreck, R. H. and A. W. Palmisano. 1973. The effects of Hurricane Camille on the marshes of the Mississippi River Delta Plain. Ecology 54:1118-1123.

de la Cruz, A. A. 1981. Differences between South Atlantic and Gulf coast marshes, p. 1020. In R. Carey, P.S. Markovits, and J.B. Kirkwood (eds.) Proceedings U.S. Fish and Wildlife Service Workshop on Coastal Ecosystems of the Southeastern United States. U.S. Fish and Wildlife Service, Office of Biological Services, Washington, DC, USA FWS/OBS-80/59.

DeLaune, R. D., S. R. Pezeshki, and W. H. Patrick, Jr. 1987. Response of coastal plants to increase in submergence and salinity. Journal of Coastal Research 3:535-546. 
Flynn, K. M., K. L. McKee, and I. A. Mendelssohn. 1995. Recovery of freshwater marsh vegetation after a saltwater intrusion event. Oecologia 103:63-72.

Godfrey, R. K. and J. W. Wooten. 1979. Aquatic and Wetland Plants of Southeastern United States. Monocotyledons. University of Georgia Press, Athens, GA, USA.

Godfrey, R. K. and J. W. Wooten. 1981. Aquatic and Wetland Plants of Southeastern United States. Dicotyledons. University of Georgia Press, Athens, GA, USA.

Guntenspergen, G. R., D. R. Cahoon, J. Grace, G. D. Steyer, S. Fournet, M. A. Townson, and A.L. Foote. 1995. Disturbance and recovery of the Louisiana coastal marsh landscape from the impacts of Hurricane Andrew. Journal of Coastal Research SI21:324-339.

Hacker, S. D. and M. D. Bertness. 1999. Experimental evidence for factors maintaining plant species diversity in a New England salt marsh. Ecology 80:2064-2073.

Hartman, J. M. 1988. Recolonization of small disturbance patches in a New England salt marsh. American Journal of Botany 75;1625-1631.

Howard, R. J. and I. A. Mendelssohn. 1999a. Salinity as a constraint on growth of oligohaline marsh macrophytes. I. Species variation in stress tolerance. American Journal of Botany 86:785-794. 
Howard, R. J. and I. A. Mendelssohn. 1999b. Salinity as a constraint on growth of oligohaline marsh macrophytes. II. Salt pulses and recovery potential. American Journal of Botany 86:795-806.

Latham, P. J., L. J. Pearlstine, and W. M. Kitchens. 1991. Spatial distributions of the softstem bulrush, Scirpus validus across a salinity gradient. Estuaries 14:192-198.

McCune, B. and J. B. Grace. 2002. Analysis of Ecological Communities. MjM Software Design, Gleneden Beach, OR, USA.

McCune, B. and M. J. Mefford. 1999. PC-ORD. Multivariate Analysis of Ecological Data, Version 4. MjM Software Design, Gleneden Beach, OR, USA.

McKee, K. L. and I. A. Mendelssohn. 1989. Response of a freshwater marsh plant community to increased salinity and increased water level. Aquatic Botany 34:301316.

Mielke, P. W., Jr. and K. J. Berry. 2001. Permutation Methods: A Distance Function Approach. Springer, New York, NY, USA.

Mitsch, W. J. and J. G. Gosselink. 2000. Wetlands, $3^{\text {rd }}$ ed. Van Nostrand Reinhold, New York, NY, USA.

Rate of Community Change 
Odum, W. E., T. J. Smith II, J. K. Hoover, and C. C. McIvor. 1984. The ecology of tidal freshwater marshes of the United States east coast: a community profile. U.S. Fish and Wildlife Service, FWS/OBS-83/17, Washington DC, USA.

Odum, W. E. 1988. Comparative ecology of tidal freshwater and salt marshes. Annual Review of Ecology and Systematics 19:147-176.

Pearlstine, L. G., W. M. Kitchens, P. J. Latham, and R. D. Bartleson. 1993. Tide gate influences on a tidal marsh. Water Resources Bulletin 29:1009-1019.

Pennings, S. C. and R. M. Callaway. 1992. Salt marsh plant zonation: the relative importance of competition and physical factors. Ecology 73:681-690.

Roman, C. T., W. A. Niering, and R. S. Warren. 1984. Salt marsh vegetation change in response to tidal restriction. Environmental Management 8:141-150.

Snow, A. A. and S. W. Vince. 1984. Plant zonation in an Alaskan salt marsh. II. An experimental study of the role of edaphic conditions. Journal of Ecology 72:669-684.

Visser, J. M., C. E. Sasser, R. H. Chabreck, and R. G. Linscombe. 1999. Long-term vegetation change in Louisiana tidal marshes, 1968-1992. Wetlands 19:168-175. 
Warren, R.S. and W.A. Niering. 1993. Vegetation change on a northeast tidal marsh: interaction of sea-level rise and marsh accretion. Ecology 74(1):96-103. 


\section{List of Tables}

Table 1. Life history characteristics and mean stem counts of species initially observed (June and October 2001) at each sample site. Species listed had a frequency of greater than 5\%. * indicates exotic species. Plant authorities and life history from Godfrey and Wooten $(1979,1981)$

Table 2. Results of community change based on reciprocal transplant experiment across a salinity gradient. FR=Freshwater site (B1), FR/IN=Freshwater/intermediate site (B2), $\mathrm{IN}=$ Intermediate site (B3), BR=Brackish site (B4).

Table 3. The plant communities that most resemble the transplanted sod community are listed for each sample point. When the transplanted sod statistically resembled $(p \leq 0.05) a$ vegetation community at more than one site, the sites that most strongly resembled the transplanted sod are listed first and then in descending order of similarity. Plant communities in which there is no difference $(p \leq 0.05)$ between the transplanted sod and the adjacent communities are italicized and bolded. FR=Freshwater site (B1), FR/IN=Freshwater/intermediate site (B2), IN=Intermediate site (B3), BR=Brackish site (B4).

Table 4. Species and stem changes of all reciprocal transplant combinations.

FR=Freshwater site (B1), FR/IN=Freshwater/intermediate site (B2), IN=Intermediate site (B3), $\mathrm{BR}=\mathrm{Brackish}$ site (B4). 
List of Figures

Figure 1. Location of the study site and transplant sample sites. Approximate zones of interstitial soil salinity in the project area are labeled on the map.

Figure 2. Water and salinity levels from October 2001 to June 2003. A. The percent of time that water levels $(\mathrm{cm})$ were equaled or exceeded for all four sample sites. Inset is an expansion of water depths from $0-12 \mathrm{~cm}$. B. The percent of time that interstitial salinity levels (ppt) were equaled or exceeded for all four sample sites.

Figure 3. Change in community structure and composition through time for all transplant combinations. The lines below zero indicate the separation or difference between the plant community composition and structure of the transplanted donor sod and the control sod at the location of origin (for example, the Freshwater sod (B1) transplanted to the Freshwater/intermediate site (B2) is the change between the donor sod B1 moved to site B2 compared to a control sod at site B1). Points overlaid with an * are statistically significant at $p \leq 0.05$. The lines above zero indicate the absolute value of the cumulative change between the transplanted donor sod and the control sod at the location of origin. The top two panels are graphs of transplant combinations with a mean difference in salinity between donor and receiver plots of less than $1.0 \mathrm{ppt}$. The bottom two panels illustrate transplant combinations with a mean difference in salinity between donor and receiver plots of greater than $1.0 \mathrm{ppt} . \mathrm{FR}=$ Freshwater site $(\mathrm{B} 1)$, $\mathrm{FR} / \mathrm{IN}=$ Freshwater/intermediate site (B2), $\mathrm{IN}=$ =Intermediate site (B3), $\mathrm{BR}=\mathrm{Brackish}$ site (B4). 


\section{Sample Sites}

\section{Tidal Fresh/Inter- Inter-}

$\begin{array}{ccccccc} & \text { Life History } & \text { Mode of } & \text { Freshwater } & \text { mediate } & \text { mediate } & \text { Brackish } \\ \text { Species } & \text { Habit } & \text { Colonization } & \text { (site B1) } & \text { (site B2) } & \text { (site B3) } & \text { (site B4) }\end{array}$

Agalinis purpurea (L.) Pennell

*Alternanthera philoxeroides

(Mart) Griseb.

Aster elliottii T. \& G.

Bidens laevis (L.) BSP.

Bidens mitis Michx.) Sherff.

Cicuta mexicana Coult. \& Rose

Eleocharis montevidensis Kunth

Eleocharis quadrangulata (Michx.)

R. \& S.

Eleocharis spp.

Flowering Herb-unidentified

Galium tinctorium L.

Hydrocotyle umbellata $\mathrm{L}$.

Iris hexagona Walt.

Juncus marginatus Rostk.

Lilaeopsis chinensis (L.) Kuntze

*Murdannia keisak (Hassk.)

Hand.-Mazz.

Phyla lanceolata (Michx) Greene

Polygonum saggitatum L.

Polygonum sp.

Pontederia cordata L.

Saggitaria lancifolia L.

Saggitaria latifolia Willd.

Scirpus validus Vahl annual

seed

9

perennial

perennial

annual

annual

perennial

perennial

perennial

perennial

annual

perennial

perennial

perennial

perennial

perennial

ammual

perennial

anmual (vine)

annual or perennial

perennial

perennial

perennial

perennial

\section{rooting stems}

seed, rhizomes

seed

seed

seed, floating tubers

seed, rhizomes

seed, rhizomes

seed, rhizomes

seed

seed

rooting stems

seed, rhizomes

seed, rhizomes

seed, thizomes

seed, forms dense

$$
\text { mats }
$$

seed, rooting stems

seed

seed

seed, rhizomes

seed, rhizomes

seed, rhizomes

seed, rhizomes
105

467

237 
Spartina cynosuroides (L.) Roth

Typha angustifolia L.

Zizaniopsis milacea (Michx)

Doell. \& Asch seed, rhizomes

seed, rhizomes

seed, rhizomes
20

Rate of Community Change

Wetzel et al

$1 / 5 / 2005$

Page 27 
Table 2

\begin{tabular}{|c|c|c|c|c|c|c|c|c|}
\hline \multicolumn{4}{|c|}{ Fresh To More Saline } & \multirow{3}{*}{$\begin{array}{c}\text { Mean } \\
\text { Difference in } \\
\text { Salinity } \\
\text { Between Donor }\end{array}$} & \multicolumn{4}{|c|}{ Saline To More Fresh } \\
\hline & Time to & Time To & Rate of & & Rate of & Time To & Time to & \\
\hline Donor Sod & Sustained Plant & Leveling off in & Cumulative & & Cumulative & Leveling off in & Sustained Plant & Donor Sod \\
\hline Transplanted to & Community & Cumulative & Community & and Receiver & Community & Cumulative & Community & Transplanted to \\
\hline Receiver Plot & Change & Change Curve & Change (Test & Plots 2000. & Change (Test & Change Curve & Change & Receiver Plot \\
\hline Compared to Donor & $(p \leq 0.05)$ & (months) & Statistic, T /30 & $2003(\mathrm{ppt})$ & Statistic, T/30 & (months) & $(p \leq 0.05)$ & Compared to Donor \\
\hline Sod Control & (months) & & months) & & months) & & (months) & \\
\hline$\overline{F R} \rightarrow$ FR/IN & $6^{\mathrm{a}}$ & 30 & 0.25 & 0.18 & 0.09 & 10 & 10 & FR/IN $\rightarrow$ FR \\
\hline $\mathrm{FR} / \mathrm{NN} \rightarrow \mathbb{N}$ & $6^{b}$ & 30 & 0.14 & 0.70 & 0.14 & 22 & 10 & $\mathrm{IN} \rightarrow \mathrm{FR} / \mathrm{N}$ \\
\hline $\mathrm{FR} \rightarrow \mathrm{N}$ & $18^{\mathrm{a}}$ & 30 & 0.27 & 0.87 & 0.25 & 30 & 18 & $\mathrm{IN} \rightarrow \mathrm{FR}$ \\
\hline $\mathrm{IN} \rightarrow \mathrm{BR}$ & 10 & 30 & 0.21 & 4.71 & 0.41 & 30 & $18^{\mathrm{a}}$ & $\mathrm{BR} \rightarrow \mathrm{NN}$ \\
\hline $\mathrm{FR} / \mathrm{IN} \rightarrow \mathrm{BR}$ & 10 & 18 & 0.09 & 5.40 & 0.25 & 30 & 18 & $\mathrm{BR} \rightarrow \mathrm{FR} / \mathrm{MN}$ \\
\hline $\mathrm{FR} \rightarrow \mathrm{BR}$ & 6 & 18 & 0.14 & 5.56 & 0.26 & 22 & 18 & $\mathrm{BR} \rightarrow \mathrm{FR}$ \\
\hline Mean & 9.3 & 26.0 & 0.18 & & 0.23 & 24.0 & 15.3 & Mean \\
\hline SEM & 1.9 & 2.5 & 0.07 & & 0.11 & 3.2 & 1.7 & SEM \\
\hline
\end{tabular}

${ }^{8}$ Plant community not statistically different at 30 months (see Figure 3 ).

${ }^{b}$ Plant community not statistically different at 22 and 30 months (see Figure 3 ). 
Table 3

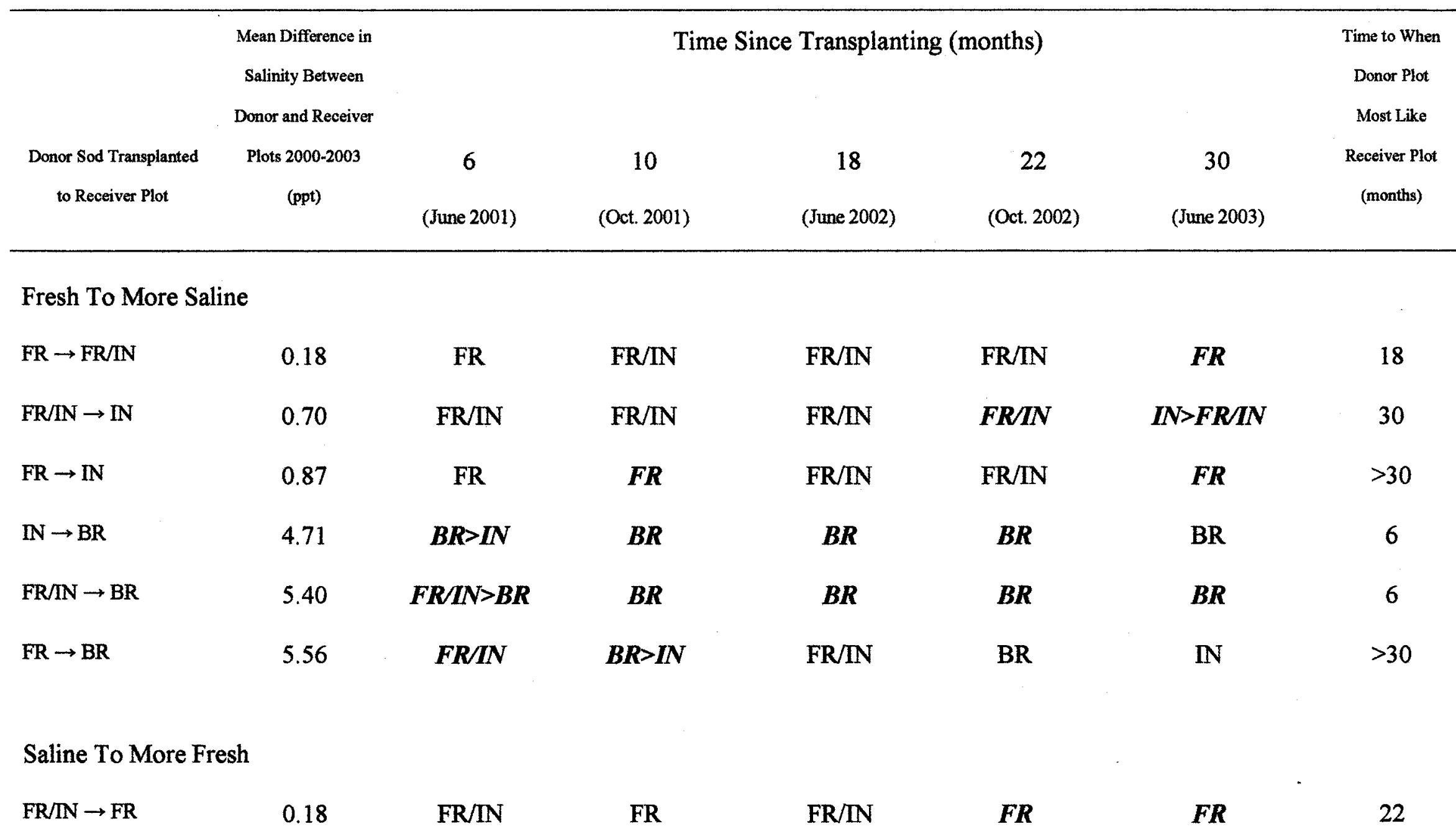




\begin{tabular}{|c|c|c|c|c|c|c|c|}
\hline $\mathrm{IN} \rightarrow \mathrm{FR} / \mathrm{IN}$ & 0.70 & $B R>I N$ & FR/IN & $\mathrm{FR} / \mathrm{IN}$ & FR/N & FRIN & 22 \\
\hline $\mathrm{IN} \rightarrow \mathrm{FR}$ & 0.87 & $\mathbf{I N}$ & $I N>B R$ & $\mathrm{FR} / \mathrm{NN}$ & FR & FRSH & $>30$ \\
\hline $\mathrm{BR} \rightarrow \mathbb{N}$ & 4.71 & $I N$ & $B R>I N>F R I N$ & $I N>F R / N$ & $I N$ & $F R / N>I N>B R$ & 6 \\
\hline $\mathrm{BR} \rightarrow \mathrm{FR} / \mathrm{IN}$ & 5.40 & BR & $I N>F R / I N>B R$ & $F R / N>I N$ & FR/IN & $F R / I N$ & 18 \\
\hline $\mathrm{BR} \rightarrow \mathrm{FR}$ & 5.56 & $I N$ & $B R>I N>F R / I N$ & FR/IN & $I N>F R / N$ & FRSH & 30 \\
\hline
\end{tabular}


Donor Sod

Sustained Group Difference

Transplanted to

Receiver Plot

Plant

$\begin{array}{cc}\text { Total No. of } & \text { No. of } \\ \text { Species in Both } & \text { Species }\end{array}$

No. of Species

Groups

Added

Lost

Murdannia
keisak
is absent at Time to Statistically Significant Difference.

Change

\section{Fresh To More Saline}

$\mathrm{FR} \rightarrow \mathrm{FR} / \mathrm{IN}$
$\mathrm{FR} / \mathrm{IN} \rightarrow \mathrm{IN}$
$\mathrm{FR} \rightarrow \mathrm{IN}$
$\mathrm{IN} \rightarrow \mathrm{BR}$
$\mathrm{FR} / \mathrm{IN} \rightarrow \mathrm{BR}$
$\mathrm{FR} \rightarrow \mathrm{BR}$

6

6

18

10

10

6

Saline To More Fresh
10

$\mathrm{FR} / \mathrm{IN} \rightarrow \mathrm{FR}$

6
8
10
10

19

13

3

23

2

5

2

8

0

10

4

$-3$

\section{$-3.8$}

$-51.5$

$+13.4$

no change

$10 \quad-3.9 ; \rightarrow 0$

$-1$

$-0.3$

$+4.0$

3

$-0.4 ; \rightarrow 0$

$+0.8$

$-0.1 ; \rightarrow 0$

$-9.3$

$+0.7$

16

$-2.0$

$-1.5 ; \rightarrow 0$

$+1.6$

$+2.5$

$17 \quad 2$

14

$-4.4 ; \rightarrow 0$

$-184.0$

$-0.1 ; \rightarrow 0 \quad+0.2$

$+0.1$ 


\begin{tabular}{lccccccccc}
$\mathrm{N} \rightarrow$ FR/IN & 10 & 8 & 3 & 2 & $-0.1 ; \rightarrow 0$ & +0.3 & - & -9.5 & $-0.3 ; \rightarrow 0$ \\
$\mathrm{NN} \rightarrow \mathrm{FR}$ & 18 & 20 & 13 & 2 & +1.3 & +8 & - & -2.6 & $-0.3 ; \rightarrow 0$ \\
$\mathrm{BR} \rightarrow \mathrm{IN}$ & 18 & 9 & 4 & 2 & - & - & - & +2.8 & +0.9 \\
$\mathrm{BR} \rightarrow \mathrm{FR} / \mathrm{IN}$ & 18 & 11 & 6 & 3 & - & +0.5 & +0.1 & +1.2 & $-0.9 ; \rightarrow 0$ \\
$\mathrm{BR} \rightarrow \mathrm{FR}$ & 18 & 21 & 17 & 2 & +11 & +14 & +0.3 & -0.4 & -0.8 \\
\hline
\end{tabular}




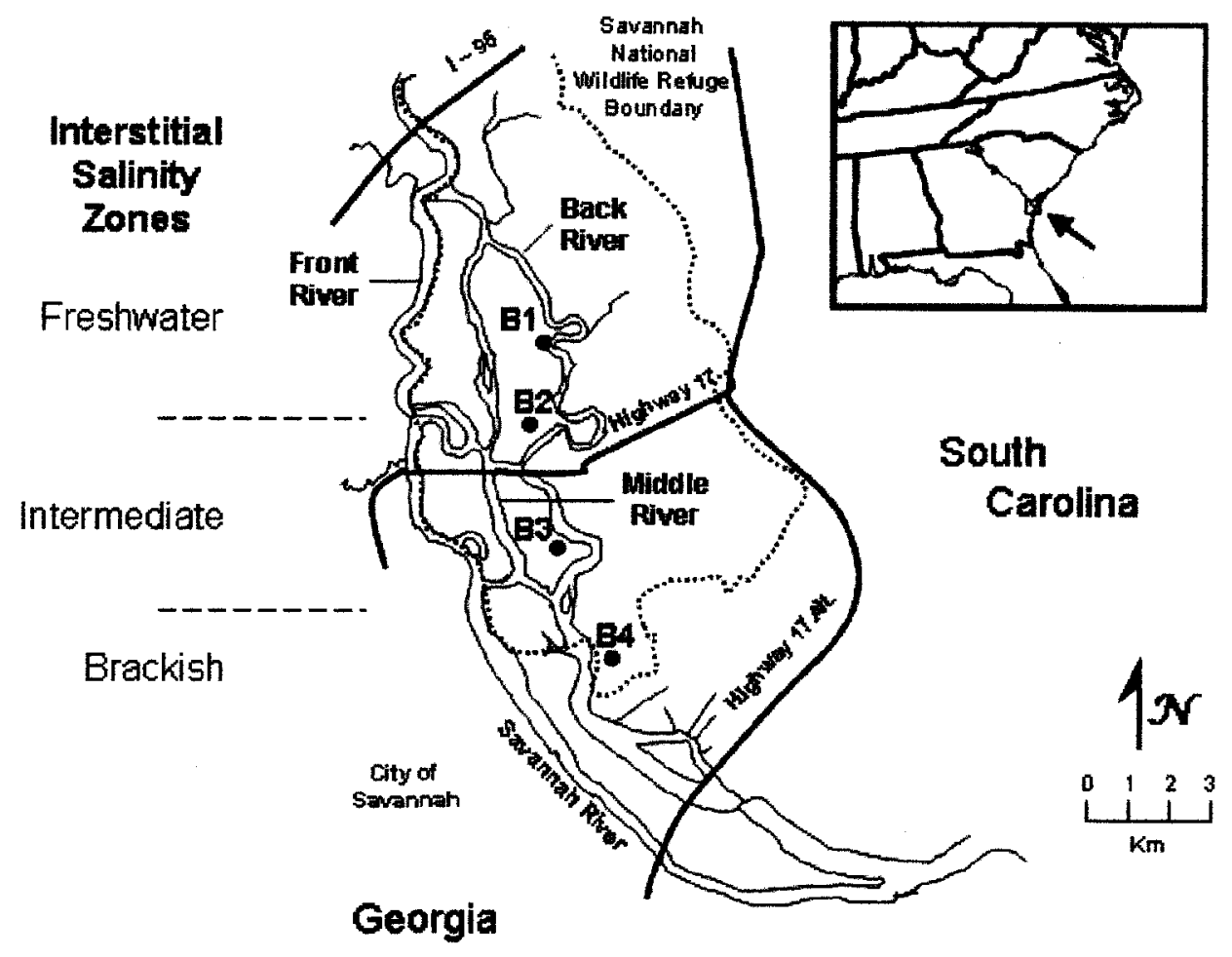

Rate of Community Change 
A.

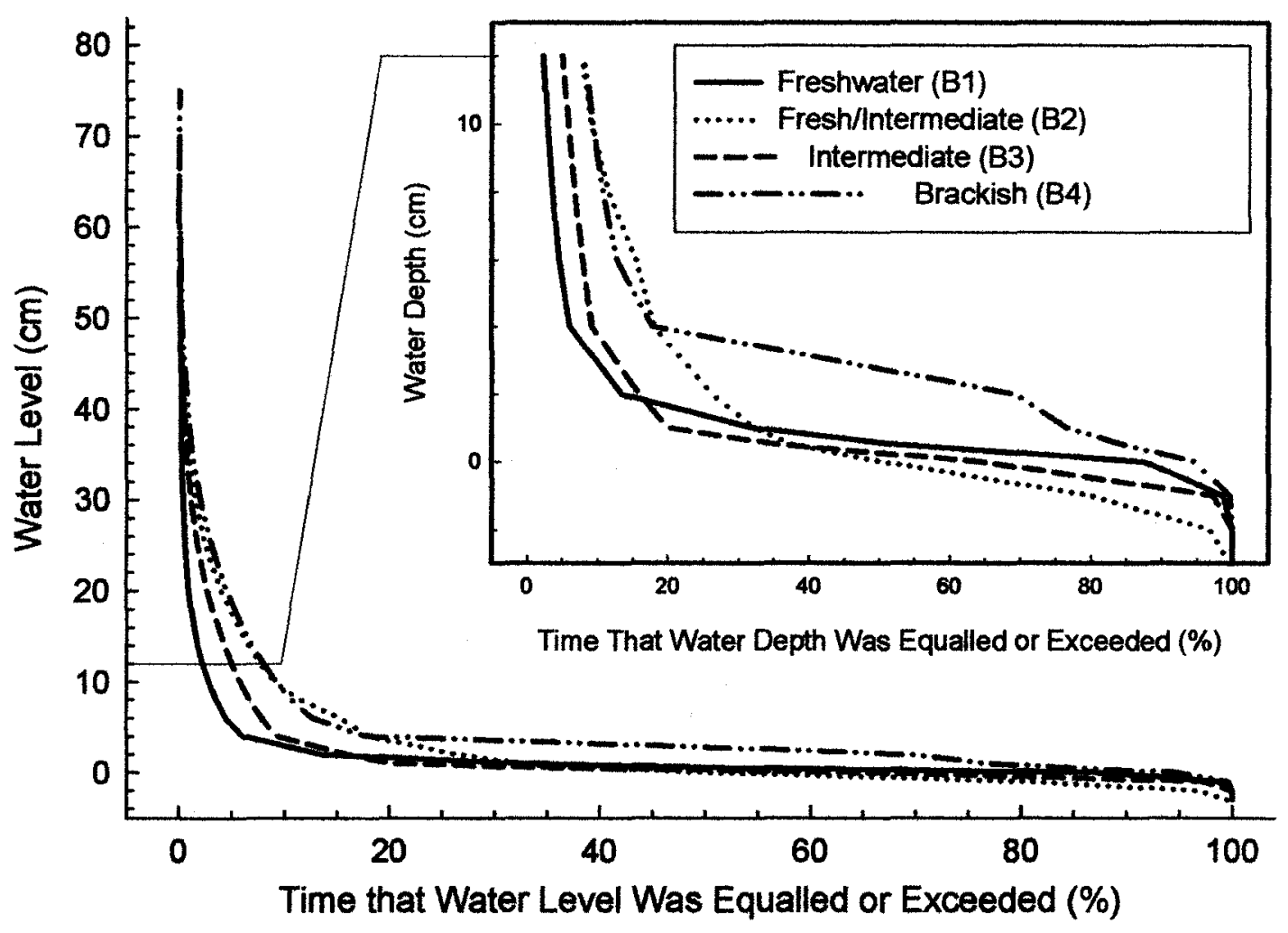

B.

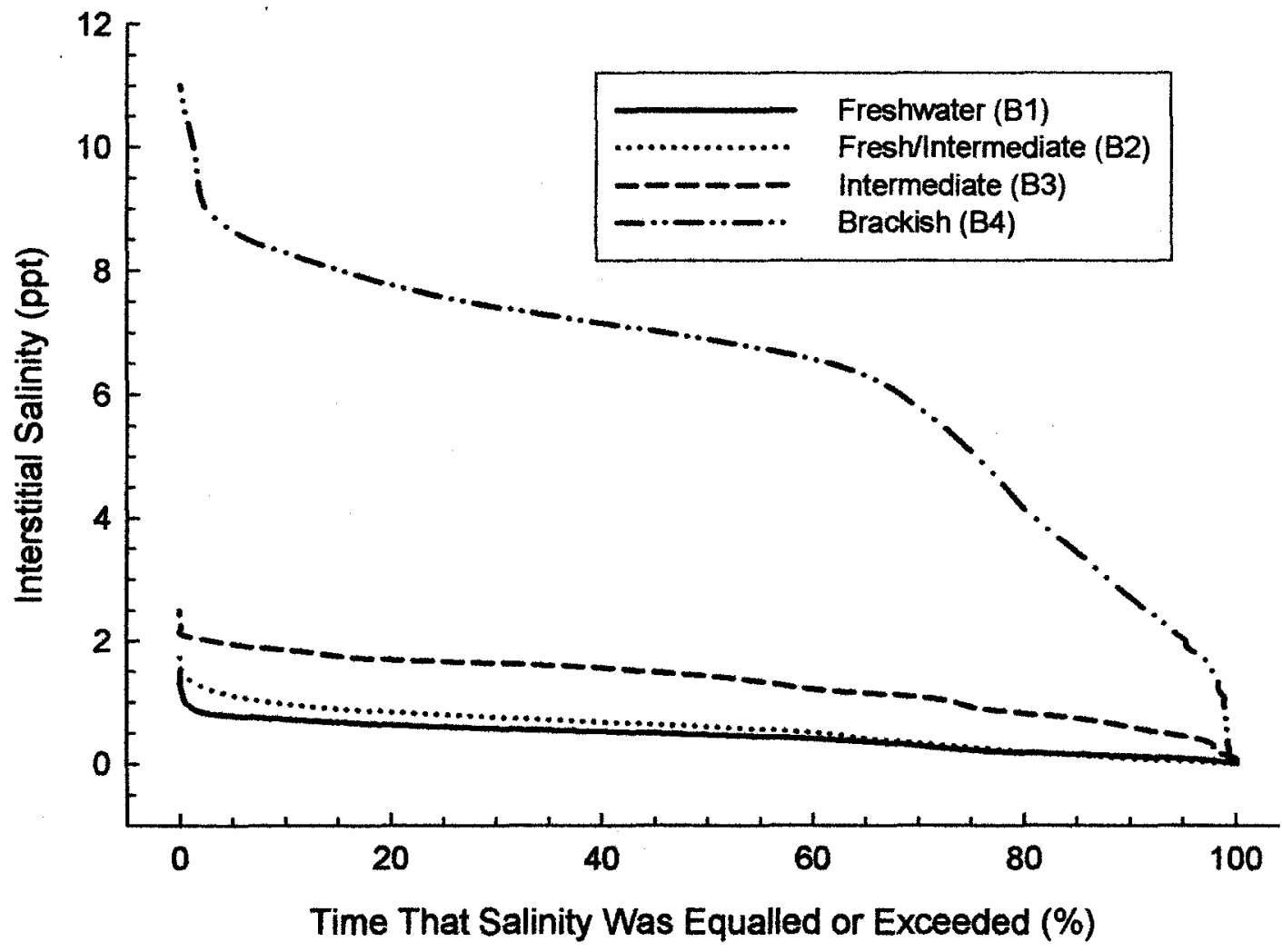

Rate of Community Change Wetzel et al $1 / 5 / 2005$ 
Fresh To More Saline
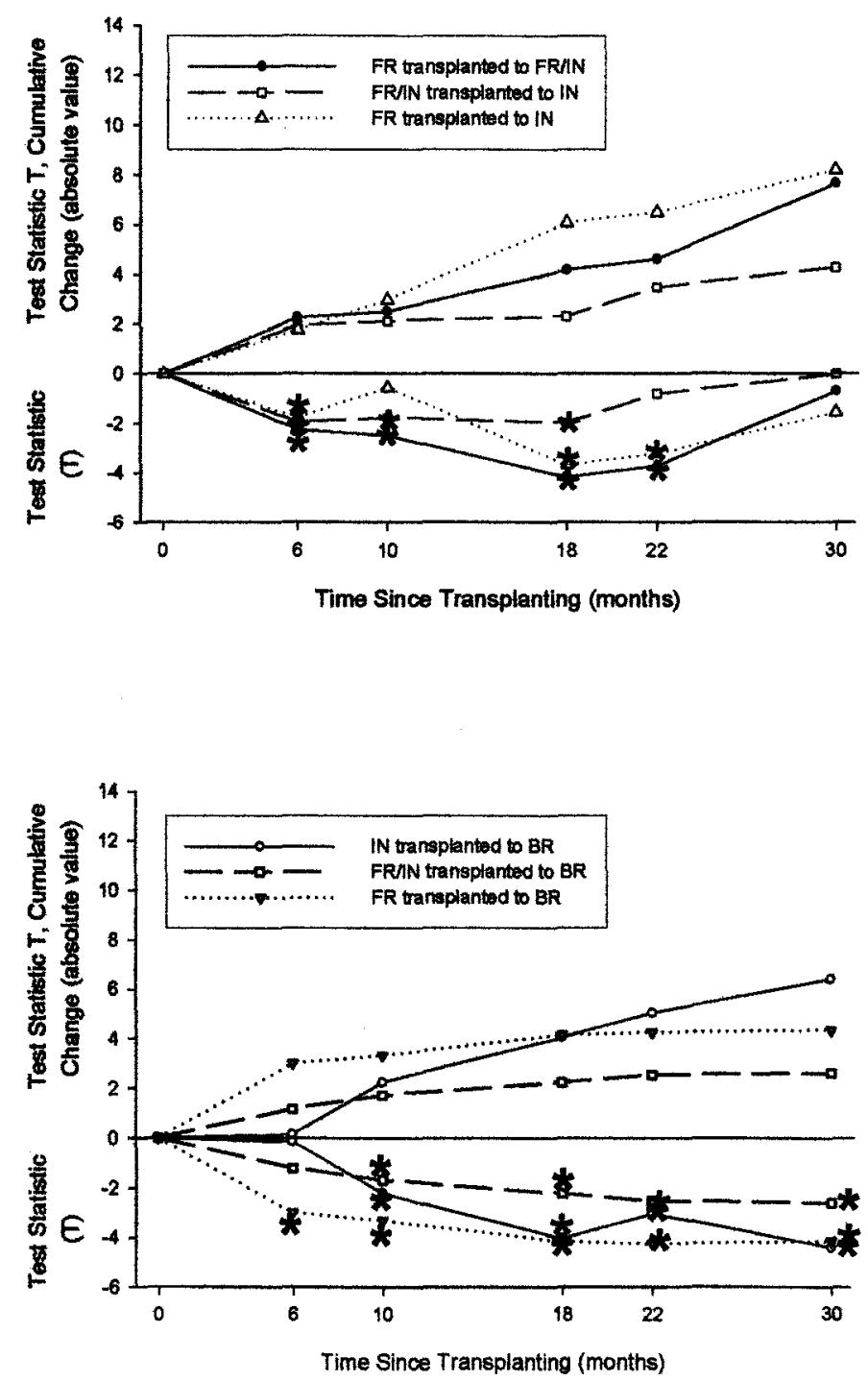

\section{Saline To More Fresh}
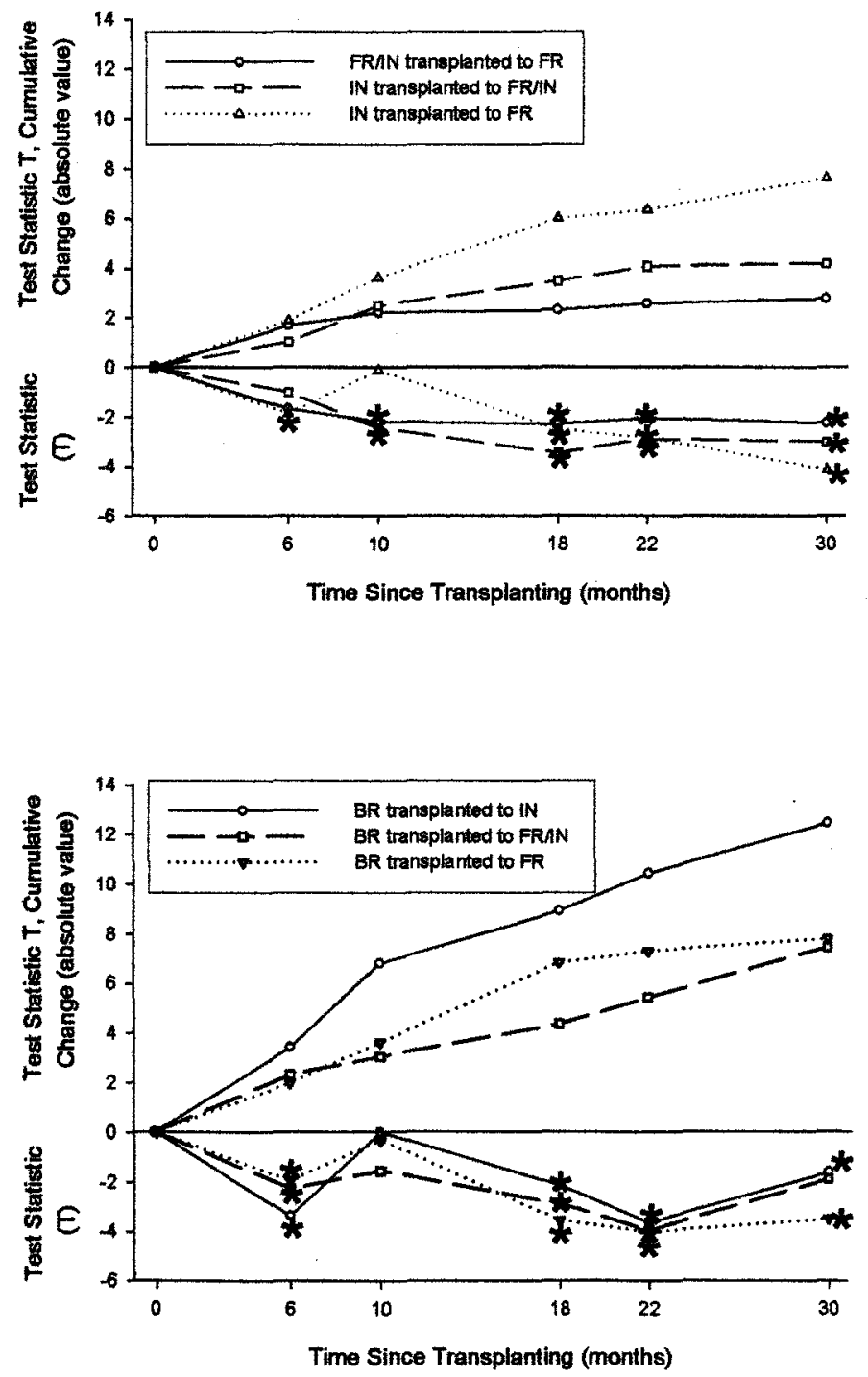